\title{
С.Ф. Золотухин*
}

Хабаровский филиал Тихоокеанского научно-исследовательского рыбохозяйственного центра, 680028, г. Хабаровск, Амурский бульвар, 13а

\section{К ПОНИМАНИЮ ИСТОРИИ И СОВРЕМЕННЫХ ПРОБЛЕМ ТРАДИЦИОННОГО РЫБОЛОВСТВА МАЛОЧИСЛЕННЫХ НАРОДОВ СЕВЕРА В ХАБАРОВСКОМ КРАЕ}

\begin{abstract}
Все амурские малочисленные народы Севера, кроме нивхов, являются потомками кочевников тунгусов-оленеводов, которых ныне называют эвенками. Начало заселения ими берегов по главному руслу р. Амур совпадает по времени с приходом русских первопроходцев. Лишь к началу 20-го в. эти народы начали жить оседло. Рыба для них являлась второстепенной пищей, морских млекопитающих они добывали случайно, с морепродуктами были почти не знакомы, торговля представляла простой обмен товарами. В настоящее время амурские малочисленные народы Севера имеют право добывать рыбу без разрешений, квот, договоров на аренду рыболовных промысловых участков, что неправильно с точки зрения управления водными биологическими ресурсами. Необходимо оптимизировать законодательство РФ в области рыболовства всего в двух случаях: ввести в понятийный аппарат закона РФ «О рыболовстве ...» термин «потребительское рыболовство» и уточнить понятие «традиционный образ жизни».

Ключевые слова: амурские малочисленные народы Севера, нанайцы, эвенки, ульчи, нивхи, палеоазиаты - оседлые народы, кочевые народы, древнее рыболовство, управление рыбными ресурсами, правила рыболовства.

Zolotukhin S.F. On understanding the history and some current problems of traditional fishery for indigenous northern nations in Khabarovsk Region // Izv. TINRO. — 2014. — Vol. 179. - P. 220-225.

All indigenous nations of the Amur River basin, except the Nivkh, are originated from Tungus nomadic reindeer herders, known now as the Evenks. Their coming to the Amur coincided in time with arrival of Russian pioneers. These peoples began to live sedentary only from the beginning of the $20^{\text {th }}$ century. Fish was not the main food for them, they hunted on marine mammals accidentally and were almost not familiar with the seafood, their trade was a simple exchange of goods. At present time the aboriginal people of the Amur River have a right to catch fish without any permits, quotas, or leasing of fishing area, that does not concern to policy of fish resources managing. For optimization of the legislation, two remarks to the Russian Federation Law «On Fisheries...» would be enough: the term «subsistence fishing» should be introduced and the concept of «traditional way of life» should be defined more precisely.

Key words: indigenous nation, Nanai, Evenk, Ulcha, Nivkh, paleoasiatic nation, migratory nation, ancient fishing, fish resources management, fishing rule.
\end{abstract}

В рыбохозяйственных проблемах сотрудникам ТИНРО-центра часто приходится выступать в качестве экспертов по вопросам взаимоотношений с коренными малочисленными народами Севера (КМНС). Ассоциации КМНС заявляют, что им необходима

* Золотухин Сергей Федорович, кандидат биологических наук, заведующий лабораторией, e-mail:sergchum2009@yandex.ru.

Zolotukhin Sergey F., Ph.D., head of laboratory, e-mail: sergchum2009@yandex.ru. 
этническая рыбная пища (амурская осенняя кета), права на круглогодичный лов рыбы. От них поступают заявки на добычу морской рыбы, крабов и таких видов морепродуктов, которые прежде никогда ими не добывались. Часто они подчеркивают, что по праву коренного населения им не требуются разрешительные документы и квоты, но нужны права на продажу рыбы в промышленных объёмах. Правы ли наши хабаровские народы Севера? На самом деле, в большинстве стран подобные права коренных народов поддерживаются правительственными актами, законами, договорами. Для того чтобы в различных ситуациях, связанных с выделением особых льгот, рыболовных промысловых участков (РПУ) и квот для КМНС, эксперты ТИНРО-центра принимали обоснованные решения, необходимо привести некоторые сведения, касающиеся истории и этнографии.

Амур был заселен человеком с эпохи палеолита. Много культур, сменяя друг друга, исчезали навсегда. К средним векам по Амуру и Сунгари оседло жили племена мохэ. В 9-13-м вв. здесь уже жили люди Покровской культуры - земледельцы, скотоводы, гончары, кузнецы, рыболовы. Они тоже навсегда исчезли после 13-го в., и берега Амура, согласно китайским хроникам, несколько веков оставались пустынными. Тунгусоязычные родовые группы, которых назовут нанайцами, ульчами, удэгейцами и др., появятся на главном русле Амура позднее.

Советские историки считали нанайцев, удэгейцев, орочей и ульчей потомками «амурских чжурчженей», укрывшихся от монголов в тайге (Окладников, Деревянко, 1973; Шавкунов, 1990; и др.). Однако это оказалось не так. Живущие ныне по Амуру малочисленные народы Севера, в отличие от известных всем со средних веков выходцев из племён мохэ - оседлых земледельцев чжурчженей, до начала 20-го в. не знали ни гончарного дела, ни земледелия, имели иной похоронный обряд и были кочевникамиоленеводами.

Очень важным вопросом истории является проблема оседлого и кочевого образа жизни. До первой половины 17-го в. по Среднему Амуру на территории маньчжурской империи Цин (1644-1911) существовали только отдельные поселения дючеров- оседлых тунгусоязычных скотоводов и земледельцев; в низовьях Амура жили нивхи - оседлые морские охотники, рыбаки и собаководы. На побережье Охотского моря обитали кочующие оленеводы и рыболовы - эвенки*. Пришли русские землепроходцы В.Д. Поярков — в 1644 г;; Е.П. Хабаров — в 1651 г. и, грабя дючеров, обеспечивали свои отряды провиантом, строили крепости и зимовья, закрепляясь на амурских берегах, даже совершая набеги на маньчжурские города в низовьях Сунгари (Шренк, 1883). Маньчжурское правительство переселило дючеров с Амура на Сунгари, решив таким образом лишить русских провианта. В итоге во второй половине 17-го в. «вместо дючеров-хлебопашцев на покинутых ими берегах Амура стали исподволь селиться гольды-ихтиофаги» (Шренк, 1883). Гольдами и другими переселившимися на Амур группами были пришедшие со стороны Станового хребта родовые группы оленеводов-тунгусов, названные позднее эвенками (Маак, 1859; Путешествие по Амуру ..., 1868**; Шренк, 1883). Эти заключения первопроходцев подтверждаются генетиками, которые считают, что по происхождению нанайцы и ульчи занимают промежуточное положение между северными тунгусами (эвенками и эвенами) и маньчжурами (Адамов, 2009). Следовательно, и русские первопроходцы, и тунгусоязычные кочевые родовые группы пришли на Амур в одно и то же время - около 300 лет назад. При этом приход русских послужил одной из причин продвижения кочевников к главному руслу р. Амур с его притоков. Исследования генетиков подтверждают молодость популяций нанайцев, ульчей (Россия), хэчже (КНР) и др. История тунгусских родов состоит из цепочек «бутылочных горлышек», когда из-за голода, эпидемий, миграций, ассимиляций их численность резко уменьшалась (Адамов, 2009). Коренными народами на Амуре являлись только оседлые палеоазиаты — нивхи.

* История Дальнего Востока ССCP с древнейших времён до XVII века: монография. М.: Наука, 1989. 375 с.

** Путешествие по Амуру и восточной Сибири А. Мичи с прибавлением статей из путешествий Г. Радде, Р. Маака и др. СПб.; М.: Типография М.О. Вольфа, 1868. 351 с. (Пер. с нем.) 
В бассейне р. Сунгари маньчжуры имели города и развитую торговлю. Маньчжурские купцы ездили вниз по Амуру к стойбищам менять материю, посуду, водку на вяленую рыбу и меха (Маак, 1859; Путешествие по Амуру ..., 1868*). Обмен товарами был основным способом торговли, но связки цинских монет с квадратным отверстием кочевники брали иногда лишь для того, чтобы пришить их на праздничную одежду или переплавить в хозяйственное изделие (Золотухин, 2013). В 15-18-х вв. Амур был почти не заселён. Торговые маршруты, плотно покрывавшие Аляску, Чукотку, Алеутские острова, не касались Амура (Fitzhugh, Crowell, 1988).

К 18-му в. на Нижнем Амуре (участок от устья р. Уссури до устья р. Амур) у кочевых тунгусоязычных оленеводов, нанайцев и негидальцев, появились стойбища: они становились больше рыболовами, чем охотниками (Маак, 1859; Шренк, 1883). Некоторые родовые тунгусоязычные группы, позднее названные удэгейцами и орочами, кочевали в более привычных для них условиях рек полугорного типа по хребту Сихотэ-Алинь. Последними как народ Нижнего Амура выделились ульчи (У, 2006; Золотухин, 2013). По побережью Охотского моря всё так же кочевали эвенки. Оседло жили лишь русские и нивхи (рис. 1).

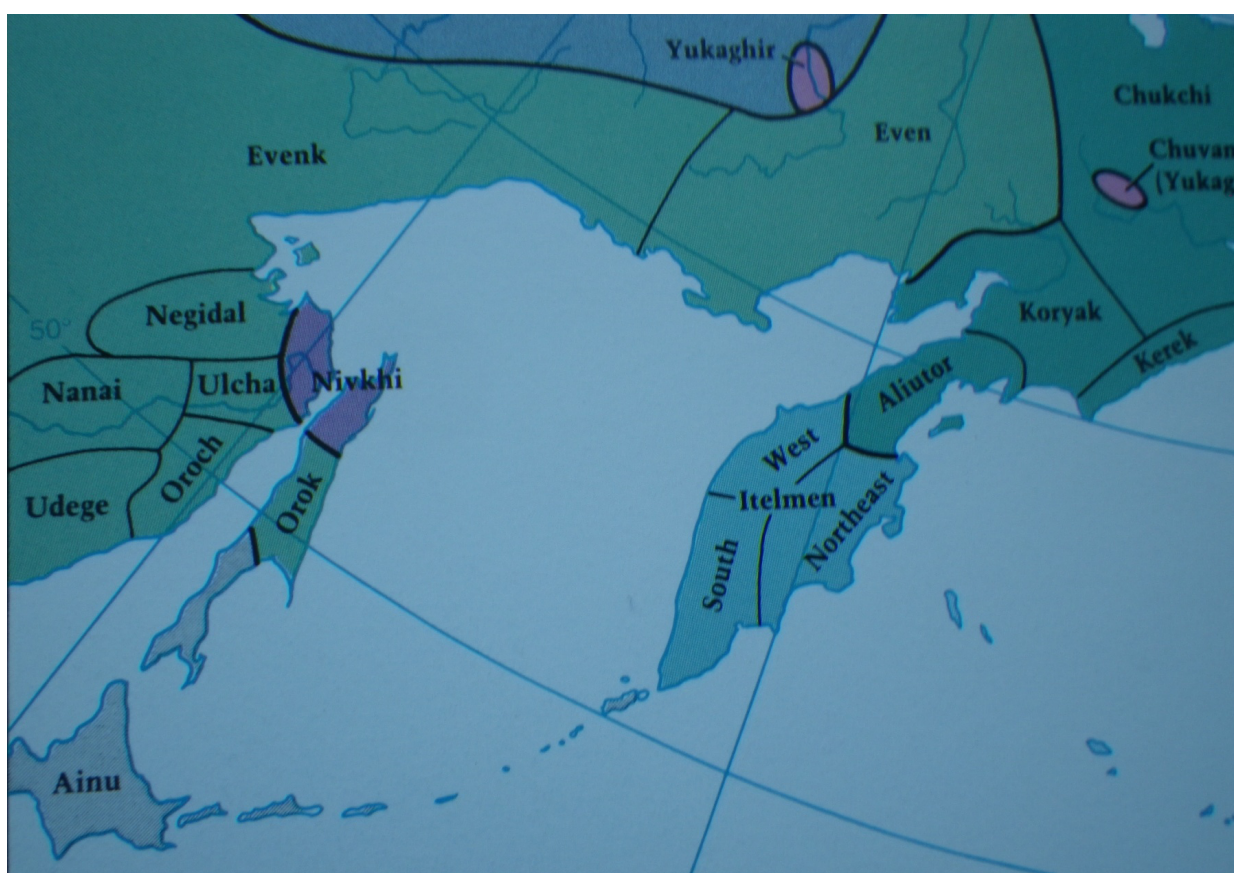

Рис. 1. Расселение народов по территории российского Дальнего Востока в 18-м в. (Fitzhugh, Crowell, 1988)

Fig. 1. Indigenous nations distribution within Russian Far East territory in the $18^{\text {th }}$ century (Fitzhugh, Crowell, 1988)

Запруды и запоры с вставленными в них корзинами-вентерями были известны по всему побережью Тихого океана, в том числе и народам Амура (Окладников, Деревянко, 1973; Золотухин, 2002). Р.И. Маак, путешествуя по Амуру в 1855 г., отмечал, что запорное рыболовство - типичная черта по всему Амуру (Маак, 1859) (рис. 2, 3).

К 18-му в. на территории современного Хабаровского края основными орудиями рыболовства были гарпуны и запорные ловушки (Золотухин, 2013). У населения Нижнего Амура определилось два типа рыболовства. Коллективное рыболовство заездкой, закидными неводами и добыча морских млекопитающих с лодок были характерны для нивхов, промысловой единицей которых, как и у любого оседлого народа, считалась деревня (Таксами, 1975). Индивидуальное рыболовство оставалось отличительной чертой нанайцев, ульчей, негидальцев, орочей, удэгейцев, промысловой единицей

* Путешествие по Амуру ... (1868). 


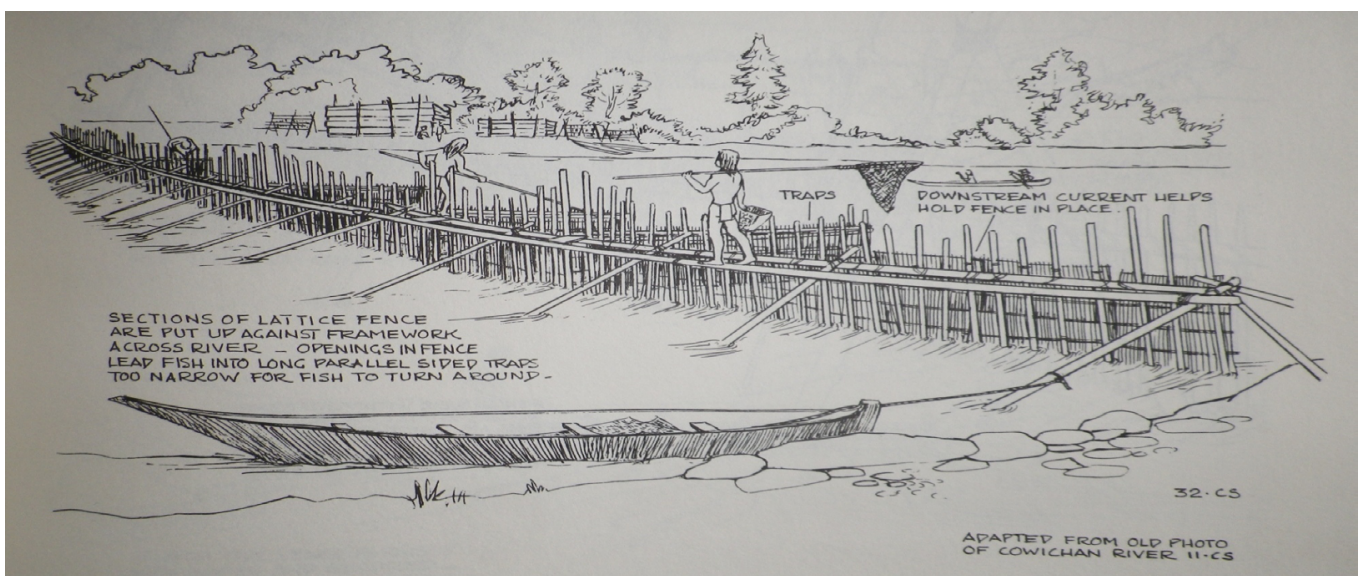

Рис. 2. Рыболовный запор с ловушками (прототип заездки) как пример коллективного рыболовства (Stewart, 1982)

Fig. 2. A fence with traps as an example of collective fishing gear (Stewart, 1982)

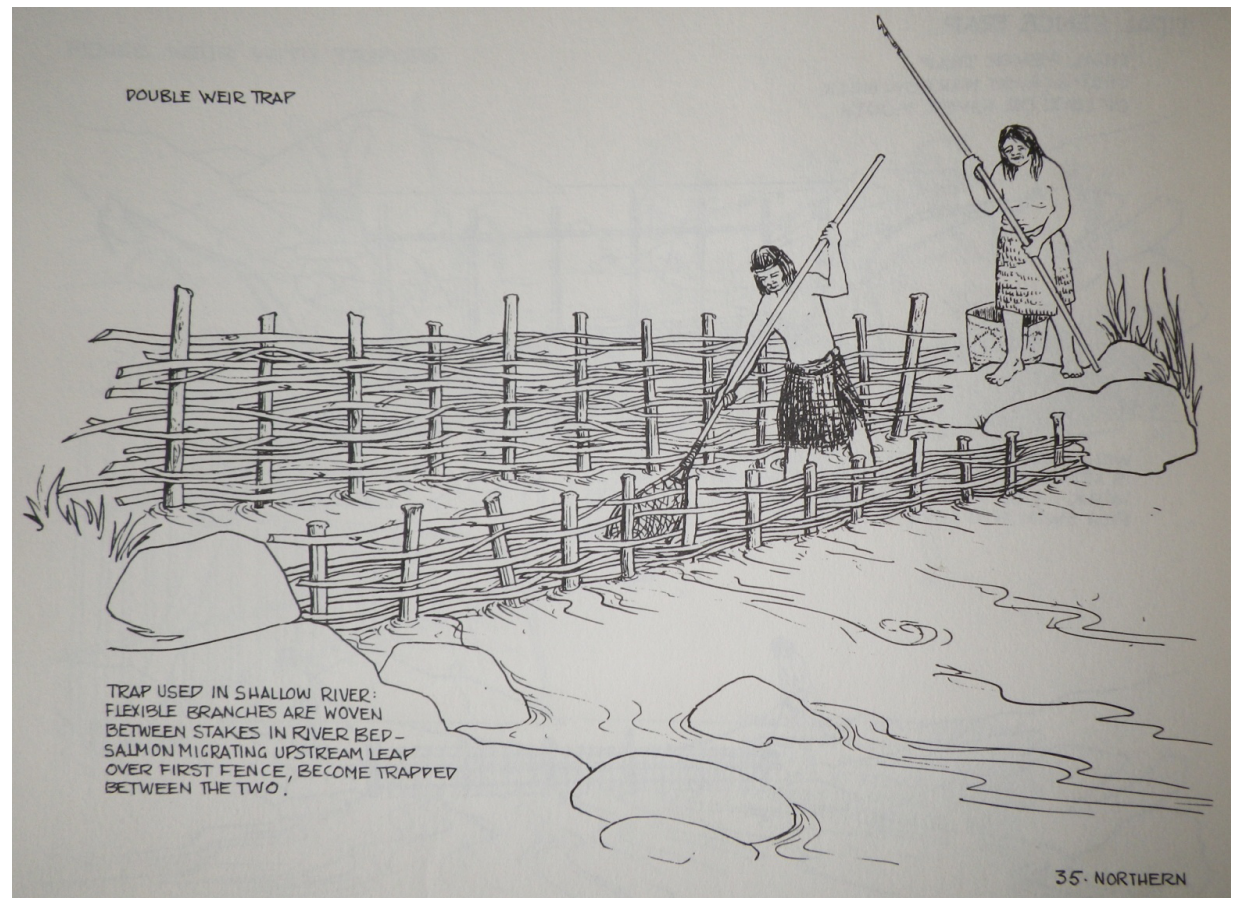

Рис. 3. Запруда на ручье как пример индивидуального рыболовства (Stewart, 1982)

Fig. 3. Double weir trap as an example of individual fishing gear (Stewart, 1982)

которых, как и у любого кочевого народа, являлась семья. Орудия индивидуального лова: сети различных конструкций (длиной 15-20 м), остроги, гарпуны, крючковые снасти (Василевич, 1969; Сем, 1973; Смоляк, 1994; Старцев, 2012; Золотухин, 2013).

Что касается белух и тюленей, больше всего их добывали нивхи для традиционного хозяйства, эвенки и орочи - только случайно (Арсеньев, 1949). Общее число белух и тюленей, добытое «инородцами», составляло не более 100 гол. в год (Арсеньев, 1949; Соловьёв, 1989).

Ни маньчжуры, ни орочи не занимались добычей морепродуктов на территории Хабаровского края. Только южнее, от бухты Терней и далее к Владивостоку, маньчжурские отходники в период 1861-1914 гг. добывали трепанга, морскую капусту, краба, гребешка (Соловьёв, 1989).

Еще в начале 1890-х гг. отмечалось, что по всему Нижнему Амуру главные рыболовы - инородцы: гиляки и гольды. Русское население не столько само занималось 
ловлей, сколько покупкою рыбы у инородцев и перепродажей её в другие места (Крюков, 1894). Однако уже через 10 лет здесь возникли крупные российские рыбные промыслы. Российский капиталистический промысел кеты и горбуши возник и развивался в устье Амура. Можно считать, что с 1880-х гг. КМНС в низовьях Амура только начали приобщаться к товарному производству, нанимаясь рабочими на русские промыслы (Алексеев, Морозов, 1989). К 20-му в. отмечается экономическое усиление русских капиталистических промыслов (в 1910 г. рыбопромышленники добыли ставными неводами в устье Амура 93 тыс. т кеты и горбуши); происходит приобщение тунгусоязычных народов к товарному производству русских, и, наконец, усиливается их оседлость. Появилась железная дорога, сформировался рынок, появились новые материалы для рыболовства: нитка-мотоуз, фабричные крючки. В традиционной экономике народов Севера на Амуре стали проявляться коммерческие черты в рыболовстве, но приход Советской власти помешал их развитию.

Итак, после исторического очерка рассмотрим современные проблемы рыболовства КМНС. Правила рыболовства от 21 октября 2013 г., ч. VIII, п. 85, разрешают КМНС лов рыбы сетью до 30 м, вентерями и удочками без оформления РПУ и без разрешения на добычу. Отчетность - ежеквартально. Однако отчетности от КМНС - почти никакой. В то же время известно, что без разрешений и без статистической отчетности об уловах управление ВБР невозможно. Кроме того, эти правила работают на браконьеров. Так, в федеральном журнале «Рыбоохрана России» № 4 за 2013 г. отмечалось: «Коренные народы, по сути дела, не ограничены в возможностях ловить рыбу, им не нужны лицензии, нет для них и каких-то других ощутимых ограничений. Этим они и пользуются. Точнее, не столько они, как силы, стоящие за их спиной» (Горбачев, 2013). На практике в Хабаровском крае в машину с браконьерской рыбой, следующей к месту продажи, надо лишь взять нанайца, который, если потребуется, скажет полицейскому, что это его улов. Так целесообразно ли разрешать КМНС Хабаровского края добычу рыбы без ограничений и без квот? Ведь коренными рыболовами они, в отличие от нивхов, не являются. Для оленеводов и кочевых охотников рыба никогда не являлась основной пищей: этнографы всегда считали рыбу второстепенным продуктом у тунгусоязычных народов. В этом отношении я солидарен со словами бывшего главы Росрыболовства А.А. Крайнего: «Если ведется традиционный образ жизни, рыба добывается традиционными орудиями лова и для пропитания, а не для продажи, которая никогда не входила в традиционный образ жизни коренных народов, — всегда поможем. В России никогда не притесняли народы, живущие на территории страны» (http://nazaccent.ru/content/8996-glava-rosrybolovstva-predlozhil-davat-lgoty-na.html).

По нашему мнению, для решения претензий КМНС необходимо оптимизировать законодательство РФ в области рыболовства всего в двух случаях:

1. Ввести в понятийный аппарат закона РФ «О рыболовстве ...» термин «потребительское рыболовство». Кстати, это должно будет относиться не только к КМНС, но и к русским, которые проживают в сельской местности, на хуторах у ненаселенных рек и ведут хозяйство, мало чем отличающееся от такового у КМНС.

2. Уточнить понятийный аппарат закона «О гарантиях прав коренных малочисленных народов РФ» в части понятия «традиционный образ жизни» и дополнить понятием «традиционная хозяйственная деятельность». Используя разрешения на лов рыбы для потребительского рыболовства, любые граждане, а не только представители КМНС, ведущие традиционное хозяйство, могли бы ловить рыбу для личного потребления без РПУ национальными или другими орудиями лова в объёмах, соразмерных их хозяйственным нуждам, укрепляя при этом пограничные области, заселяя пустынное ныне побережье и противодействуя браконьерству.

Права на коммерческое рыболовство в РФ для любого гражданина равны и вытекают из прав на аренду РПУ и квоты на ВБР, а не из прав коренного населения, к которому на Амуре можно причислить только нивхов, численность которых на 2010 г. составляла 2400 чел. 


\section{Список литературы}

Адамов Д.С. Об основных гаплогруппах Ү-хромосомы тунгусо-маньчжурских народов // The Russian Journal of Genetic Genealogy (Русская версия). — 2009. — Т. 1, № 2. - С. 40-51.

Алексеев А.И., Морозов Б.Н. Освоение русского Дальнего Востока (конец ХIX в. 1917 г.) : монография. - М. : Наука, 1989. — 224 с.

Арсеньев В.К. Дельфиний промысел // Сочинения. - 1949. - Т. 6. - С. 198-209.

Василевич Г.М. Эвенки. Историко-этнографические очерки (XVIII - начало XX в.) // Рыболовство. - Л. : Наука, 1969. - С. 80-86.

Горбачев С. Рыба в реке есть // Рыбоохрана России. - 2013. - № 4. - С. 16-31.

Золотухин С.Ф. Архаичные орудия рыболовства и их современная роль в Приморском крае // Статус пелагических и донных сообществ и условий их обитания в дальневосточных морях на рубеже XX и XXI столетий // Изв. ТИНРО. - 2002. - Т. 130. - С. 857-870.

Золотухин С.Ф. Древнее рыболовство в районе Хабаровска : монография. - Хабаровск : Ковчег, 2013. - $128 \mathrm{c}$.

Крюков Н.А. Некоторые данные о положении рыболовства в Приамурском крае : Зап. Приамур. отд. импер. русск. геогр. о-ва. Отдельный оттиск. - СПб. : Типография императорской академии наук, 1894. - 87 с.

Маак Р.К. Путешествие на Амур, совершённое по распоряжению Сибирского отдела Императорского русского географического общества в 1855 г. Р.К. Мааком. - СПб. : Издательство члена-соревнователя Сибирского отдела императорской академии наук С.Ф. Соловьёва, 1859. $211 \mathrm{c}$.

Окладников А.П., Деревянко А.П. Далёкое прошлое Приморья и Приамурья : монография. - Владивосток : ДВ книжное изд., 1973. — 439 с.

Сем Ю.А. Нанайцы. Материальная культура : монография. — Владивосток : Примиздат, 1973. - $313 \mathrm{c}$.

Смоляк А.В. Хозяйство ульчей до 1917 г. // История и культура ульчей в XVII-XX вв. Историко-этнографический очерк. - СПб., 1994. - С. 26-28.

Соловьёв $\boldsymbol{\Phi . В . ~ К и т а и ̆ с к о е ~ о т х о д н и ч е с т в о ~ н а ~ Д а л ь н е м ~ В о с т о к е ~ Р о с с и и ~ в ~ э п о х у ~ к а п и т а л и з м а ~}$ (1861-1917 гг.) : монография. — М. : Наука, 1989. - 127 с.

Старцев А.Ф. Рыболовство негидальцев в XX веке // Россия и АТР. - 2012. — № 1. C. $48-55$.

Таксами Ч.М. Основные проблемы этнографии и истории нивхов : монография. — Л. : Наука, 1975. - 238 с.

У Е.А. История ульчского рода Уды // Словесница искусств. — 2006. — № 18. — С. 77-80.

Шавкунов Э.В. Культура чжурчженей-удигэ XII-XIII вв. и проблема происхождения тунгусских народов Дальнего Востока : монография. - М. : Наука, 1990. — 282 с.

Шренк Л.И. Об инородцах Амурского края. - СПб. : Издание императорской академии наук, 1883. - T. 1. - 358 с.

Fitzhugh W., Crowell A. Crossroads of Continents. Cultures of Siberia and Alaska. - Washington : D.C. Smithsonian Institution Press, 1988. - 360 p.

Stewart H. Indian fishing. Early methods on the Northwest coast. - Seattle : Univ. Wash. Press, 1982. - $181 \mathrm{p}$.

Поступила в редакциию 2.07.14 2. 